\title{
Socialismo Moreno, Conservadorismo Pálido? Cor e Recrutamento Partidário em São Paulo e Rio de Janeiro nas Eleições de 2012*
}

\section{Luiz Augusto Campos}

Universidade do Estado do Rio de Janeiro (UERJ), Rio de Janeiro, RJ, Brasil. E-mail: lascampos@iesp.uerj.br.

\section{INTRODUÇÃO}

T ão é preciso ser um observador atento da política brasileira para 1 perceber que ela é feita basicamente por homens brancos. Uma rápida mirada pelos noticiários jornalísticos já é capaz de indicar o quanto pretos e pardos estão alijados da representação e dos demais postos de poder. Os dados estatísticos, computados nas últimas eleições nacionais, confirmam essa impressão, haja vista que quase $80 \%$ dos deputados e deputadas eleitos no último pleito se declararam brancos (Campos e Machado, 2015a). É verdade, contudo, que subrepresentação política não é uma exclusividade dos pretos e pardos: a política brasileira não é apenas branca, mas também masculina. Porém, medidas que visam corrigir a sub-representação das mulheres nos legislativos, por exemplo, já estão na pauta de debate político há algum tempo, enquanto o mesmo não pode ser dito sobre os não brancos.

Talvez por isto, tenha causado surpresa a proposta de cotas legislativas para negros, aventada no bojo da reforma política sugerida pela presi-

\footnotetext{
* Essa pesquisa não teria sido possível sem a cooperação de vários colegas. Agradeço a Thyago Simas de Oliveira, que desenhou as ferramentas informáticas necessárias à sua consecução; a Isadora Lopes Harvey, Victor Ramos, Bruno Viggiano e Leandro Guedes, que contribuíram voluntariamente classificando as fotos dos candidatos; a Carlos Machado, Danusa Marques, Flávia Biroli e Luis Felipe Miguel, que comentaram versões preliminares do texto. Agradeço, finalmente, aos pareceristas anônimos da DADOS Revista de Ciências Sociais.
}

DADOS - Revista de Ciências Sociais, Rio de Janeiro, vol. 58, no3, 2015, pp. 689 a 719. 
denta Dilma Rousseff como resposta às manifestações de junho de 2013. De autoria dos deputados Luiz Alberto (PT-BA)* e Luiz Paulo Cunha (PT-SP), o Projeto de Emenda Constitucional (PEC) 116 de 2011 propõe um sistema de voto plural, em que cada eleitor teria de escolher dois candidatos nas eleições legislativas, um dentre aqueles autodeclarados pretos ou pardos e outro concorrente no sistema universal. Ao fim do pleito, os candidatos pretos e pardos mais votados preencheriam vagas reservadas no Legislativo, sempre na proporção de dois terços da população não branca total do país, segundo o Instituto Brasileiro de Geografia e Estatística (IBGE) ${ }^{1}$.

Comparando a tramitação da PEC 116/2011 com sua repercussão na imprensa, é possível dizer que o projeto suscitou mais polêmica do que apoio (Falcão, 2013; Braga, 2013; Cardoso, 2013; Magnoli, 2013). As reações ao projeto têm diferentes motivações. Em um país cujo projeto nacional esteve historicamente ligado à ideia de democracia racial e ao elogio da miscigenação, qualquer estratégia política que dependa da diferenciação entre brancos e não brancos é polêmica. Vide a controvérsia suscitada pelas cotas raciais no ensino superior brasileiro, polêmica pública que já dura mais de dez anos e que envolveu os mais importantes setores da política, da academia e da sociedade como um todo.

Ademais, as políticas que visam aumentar a representatividade de grupos na representação política são, elas próprias, difíceis de serem justificadas apelando exclusivamente para os princípios básicos da democracia liberal. Como destacou Hanna Pitkin em seu estudo seminal sobre o conceito, a ideia de uma representação descritiva, em que o corpo de representantes é avaliado pela sua semelhança com o corpo de cidadãos, contradiz algumas premissas da própria ideia de representação política (Pitkin, 1967).

Mas, para além destas questões, é preciso destacar que pouco se sabe sobre os mecanismos sociológicos e institucionais que tornam a política nacional um espaço dominado por brancos. Não se sabe sequer em que fase da carreira política os pretos e pardos são afastados da representação. A sub-representação política deste grupo pode ser explicada por uma miríade de fatores, relacionados não apenas às escolhas eleitorais dos cidadãos, mas também a problemas no recrutamento dos quadros

\footnotetext{
*Ver lista de siglas dos partidos políticos com os respectivos significados ao final do artigo.
} 
partidários. Se pretos e pardos enfrentam dificuldades de se lançarem candidatos porque as legendas estão fechadas para eles, sua sub-representação política não pode ser atribuída à decisão dos eleitores.

O objetivo deste artigo é discutir em que medida a sub-representação política dos pretos e pardos no Brasil pode ser atribuída ao tratamento desigual que eles recebem quando os partidos políticos nacionais formam suas listas eleitorais. A partir de um levantamento sobre a cor dos candidatos a vereador nas eleições ocorridas em 2012 nos dois maiores municípios brasileiros - São Paulo e Rio de Janeiro - tenta-se estabelecer até que ponto os critérios de recrutamento de candidaturas variam de partido para partido e como tais critérios influenciam na sub-representação dos não brancos.

Embora já existam pesquisas que buscam dimensionar a sub-representação política dos negros, elas costumam se focar no topo da pirâmide, isto é, na presença ou ausência desse contingente no legislativo federal (cf. Campos e Machado, 2015a; Johnson III, 1998; Paixão e Carvano, 2008; Unegro, 2011). Tal enfoque perde de vista que a marginalização deles em relação à política provavelmente ocorre nas partes mais baixas da carreira política. Como os estudos de recrutamento político vêm chamando a atenção (ver, por exemplo, Norris, 1997; Perissinotto e Miríade, 2009), aqueles que conseguem se eleger deputados federais ou senadores já passaram por incontáveis filtros políticos e, por isto, é difícil localizar a partir deles quais destes filtros têm mais impacto na sub-representação dos pretos e pardos. Logo, a opção feita aqui pelas eleições para vereador se justifica porque elas são a etapa inicial da carreira política.

Diante da carência de registros oficiais sobre a cor autodeclarada dos candidatos a vereador ${ }^{2}$, optou-se por submeter as fotos dos quase três mil candidatos nos dois municípios, obtidas no site do Tribunal Superior Eleitoral (TSE), à classificação de uma equipe de pesquisadores. Isto justifica em parte a opção por operar com apenas dois municípios brasileiros. Trabalhar com as fotos de todos os candidatos a vereador no Brasil ou em um estado da Federação dificultaria sobremaneira a classificação. Analogamente, optar por uma análise por amostragem também dificultaria a construção de inferências sobre dinâmicas partidárias, haja vista que estas variam bastante de acordo com as regiões do país. 
Finalmente, há que se destacar a importância de São Paulo e Rio de Janeiro, não apenas enquanto polos econômicos do país, mas também como municípios idiossincráticos para o estudo da relação entre raça e poder. Além de ser uma unidade da Federação central no jogo político nacional, São Paulo se distingue também por possuir elites políticas altamente diversificadas do ponto de vista socioeconômico. Justamente por isto, os dados obtidos permitem entender até que ponto a subrepresentação dos pretos e pardos na política pode ser vista como um epifenômeno das desigualdades de classe. Já o município do Rio de Janeiro é particularmente relevante para a compreensão destas dinâmicas. Sociologicamente, trata-se do segundo município com maior proporção de não brancos do país. Politicamente, o Rio de Janeiro foi o palco da articulação de um setor importante do movimento negro brasileiro e, também, de construção de ideologias políticas voltadas para os não brancos, como foi o caso do trabalhismo varguista e seu herdeiro moderno, o socialismo moreno empunhado pelo PDT. Ademais, a quantidade de partidos competitivos no Rio é alta, o que permite entender melhor as particularidades de cada um deles.

O que se segue está dividido em cinco partes. Na primeira delas, discuto em que medida a sub-representação dos pretos e pardos na política pode ser vista como um déficit democrático. Em seguida, resenho os principais trabalhos sobre cor e eleições com o objetivo de mostrar que tal bibliografia costuma se centrar mais na demanda dos eleitores do que na oferta partidária de candidatos. A terceira seção esclarece as escolhas metodológicas feitas pelo estudo. Na quarta parte, discuto os resultados obtidos para, na quinta seção, delinear algumas conclusões gerais.

\section{PRETOS, PARDOS E A POLÍTICA}

Ainda que as pesquisas sobre raça e política sejam relativamente raras (Oliveira, 2002), desde a década 1980 são feitos levantamentos que buscam dimensionar a sub-representação de pretos e pardos na política. De acordo com Olie Johnson III, o percentual de negros na Câmara dos Deputados entre 1983 e 1987 foi de 0,84\%; pulou para 2,05\% entre 1987 e 1991 e atingiu 2,92\% entre 1995 e 1999 (1998:103). Atualizando esses dados para o período entre 2007 e 2008, o Laboratório de Análises Econômicas, Históricas, Sociais e Estatística das Relações Raciais (Laeser) concluiu que dos 513 deputados federais eleitos em 2006, 11 eram pretos e 35 pardos, perfazendo um conjunto de $8,9 \%$ de não bran- 
cos no total (Paixão e Carvano, 2008:148). Já a ONG Unegro (União de Negros pela Igualdade) considerou que em 2010, o Congresso Nacional continha " 43 deputados e deputadas negros, chegando ao índice de $8,5 \%$ de negros no Parlamento brasileiro" (Unegro, 2011). A partir do primeiro levantamento oficial sobre a cor/raça dos candidatos eleitos, feito pelo TSE em 2014, Campos e Machado afirmam que, dentre os 513 deputados que assumiram a Câmara em 2015, 71,9\% eram homens brancos, $18,1 \%$ eram homens não brancos, $8 \%$ eram mulheres brancas e apenas 2\% eram mulheres não brancas (Campos e Machado, 2015a).

Se mais da metade dos brasileiros se declarou preta ou parda no último censo de $2010^{3}$, fica evidente a sub-representação dos grupos raciais no Parlamento. Ainda que seja possível colocar em dúvida os métodos de classificação racial utilizados nos estudos supracitados ${ }^{4}$, ou a validade da autodeclaração dos candidatos computada pelo TSE, em todos os casos o percentual de não brancos na representação é irrisório quando comparado ao de não brancos na população como um todo.

Mas apesar deste déficit de representação descritiva, é preciso questionar por que a sub-representação dos não brancos deve ser encarada como um problema político. Em vários aspectos, a adoção de mecanismos eleitorais para garantir a representação de grupos contraria cânones importantes da democracia liberal. Um dos pressupostos da democracia eleitoral é o princípio utilitarista de que cada cidadão é o melhor juiz dos seus interesses. Deste ponto de vista, regras que visem redistribuir votos de modo a facilitar a ascensão política dos membros de alguns grupos seriam contrárias à decisão de cada eleitor (Miguel, 2000).

A crítica à representação de grupos não está restrita aos defensores de uma concepção estritamente utilitária da representação política. Hanna Pitkin, por exemplo, é uma autora que dedicou sua obra mais importante à ampliação do sentido da ideia de representação política, distanciando-se, assim, dos significados tradicionais atribuídos ao termo. Porém, isso não a impediu de criticar as concepções que defendem que um corpo de representantes só é verdadeiramente democrático quando espelha ou reflete o corpo de cidadãos. Para ela, estas concepções dão tanta importância às semelhanças entre representados e representantes que o modo como estes últimos agem fica em segundo plano (1967:226). Consequentemente, a persecução da vontade popular deixa de ser vista como um problema de ação política para ser redu- 
zida a uma questão de similitude identitária. Desta ótica, a amostragem aleatória seria um método muito mais eficaz para compor um corpo de representantes do que as eleições (ibidem:226).

No entanto, as críticas de Pitkin incentivaram todo um conjunto de autoras e autores a produzirem justificativas para a representação de grupos que fossem além da ideia de uma representação descritiva. Para Anne Phillips, por exemplo, a representação de grupos seria importante para desconstruir estereótipos identitários; permitir modalidade de agregação de agenda para além dos partidos políticos; proteger grupos politicamente excluídos e, por isto, socialmente mais vulneráveis; e para a pluralização da agenda política (Phillips, 1995:39). Ademais, ela parte do pressuposto de que nenhuma sociedade pode se dizer realmente democrática se exclui sistematicamente determinados grupos da política. Logo, medidas para incluir grupos na representação são exigências de uma sociedade que se pretende igualitária em suas oportunidades (Phillips, 1991). Jane Mansbridge, por seu turno, considera que uma representação especial para grupos se torna mais justificável em contextos sociais em que há uma crise de confiança entre eleitos e eleitores de um grupo sub-representado; clivagens políticas tradicionais entram em crise e interesses tornam-se imprecisos; há um contexto histórico que atribui a um dado grupo uma inabilidade intrínseca para o governo; ou quando a deliberação sobre políticas para grupos perdem legitimidade por não incorporarem tais grupos no debate (Mansbridge, 1999).

Segundo Will Kymlicka, políticas específicas para colocar grupos no Parlamento não partem necessariamente do entendimento de que a representação deve espelhar a sociedade. Trata-se, antes de permitir que grupos sistematicamente discriminados possam ascender à política, seja como meio de denúncia dessa discriminação, seja como forma de romper as barreiras colocadas a eles e que tem reflexos políticos (1995:141). Já Iris Marion Young insiste que nenhuma deliberação pública pode se dizer democrática se exclui perspectivas sociais oprimidas e se esta exclusão contribui para reforçar tal silenciamento (2000). Tal argumento se aproxima daquele esposado por Melissa Williams, para quem a representação especial é uma forma de dar voz a grupos marginalizados, aumentar a confiança entre representantes e representados e, finalmente, recuperar a memória das discriminações que eles sofreram (2000). 
Todavia, tais justificações costumam esbarrar em dois problemas fundamentais. De um lado, a ênfase nas chamadas "políticas de presença" para grupos marginais tende a colocar em segundo plano a importância de uma "política de ideias" (Phillips, 1995), o que pode ameaçar a autonomia dos eleitores em terem suas escolhas respeitadas, a autonomia dos representantes em suas ações e, sobretudo, ameaçar as relações de accountability entre eles. Do outro lado, os defensores das políticas de presença sempre têm de lidar com o risco de uma essencialização das clivagens identitárias (cf. Phillips, 2007; Young, 2000:87-102), já que a inclusão de grupos marginais depende de uma oficialização e congelamento das identidades culturais.

A consciência destes riscos tem feito com que os defensores das políticas de presença considerem com mais atenção o papel desempenhado pelos partidos políticos na inclusão de grupos marginalizados. Ademais, a multiplicação de trabalhos em torno do recrutamento de candidaturas tem contribuído para uma compreensão mais fina dos reais motivos da sub-representação política de determinados grupos (Norris e Lovenduski, 1995). Por conta disto, medidas que garantam uma dada composição das listas partidárias ou mecanismos internos aos partidos de seleção de seus candidatos têm substituído o lugar outrora ocupado pelas cotas parlamentares (Htun, 2004). Frequentemente, esta reorientação tem a vantagem de contornar os problemas supracitados e, sobretudo, atuar nos filtros que de fato excluem tais grupos da representação. Em contextos nos quais a sub-representação de um dado grupo não reflete as preferências enviesadas dos eleitores, diversificar a oferta de candidaturas pode ser suficiente para garantir a representação de determinados grupos sem violar a autonomia dos eleitores.

A bibliografia sobre raça e eleições no Brasil está basicamente concentrada na existência ou não de uma orientação étnica no sufrágio. Diferentes autores buscaram estabelecer em que medida não brancos tendem a votar em candidatos de uma dada cor ideológica ou em candidatos da mesma cor que eles. Embora haja uma confluência nos resultados desses estudos, os dados que eles mobilizam não são conclusivos. Ademais, tal literatura tem focado nas preferências dos eleitores, deixando em segundo plano a oferta de candidaturas, elemento fundamental para a compreensão do fenômeno. 


\section{PRETOS, PARDOS E AS ELEIÇÕES}

Ainda que seja frequente encontrar nas obras dos sociólogos e antropólogos das relações raciais brasileiras hipóteses sobre a relação não brancos e a política (Oliveira, 2002), é somente a partir da década de 1960 que surgem estudos dedicados exclusivamente à relação entre não brancos e eleições. A despeito da pluralidade de abordagens metodológicas e interesses de pesquisa, subjaz a essa literatura uma indagação comum, passível de ser genericamente formulada da seguinte maneira: em que medida as clivagens raciais existentes no Brasil se relacionam com preferências identitárias ou ideológico-políticas? De modo geral, tais estudos buscam estabelecer até que ponto existe uma correlação entre as preferências dos eleitores por determinados candidatos, partidos, ideologias etc. e o modo como eles se percebem ou são percebidos em termos raciais.

Tal correlação já era considerada relevante no trabalho pioneiro de Amaury de Souza sobre a interface da raça com a política no Brasil urbano. Mesmo reconhecendo os esforços históricos empreendidos pela elite nacional para conter a ascensão social dos ex-escravos e impedir a formação de uma identidade de grupo entre eles, Souza acreditava que a raça era um fator interveniente importante para a explicação de determinados comportamentos políticos (1971:62-67). Isso se confirmava, a seu ver, em um survey realizado em 1960, com uma amostra dos eleitores da cidade do Rio de Janeiro, em que há uma constante preferência do eleitorado negro pelos candidatos trabalhistas. Para ele, isto se explicava parcialmente pela adesão da população negra ao varguismo, adesão esta motivada não apenas pela melhoria das condições de vida da população negra durante a era Vargas, mas também pelo fato de o trabalhismo tratar o negro como símbolo da emergente noção de "povo brasileiro" (ibidem:64).

Em um estudo realizado quase 15 anos depois, já no contexto de redemocratização do país, Gláucio Ary Dillon Soares e Nelson do Valle Silva defendem que a preferência dos eleitores não brancos pelo trabalhismo permanecia, ainda que sob novas roupagens partidárias e ideológicas (1985:258). Para testar esta hipótese, Soares e Silva comparam a votação recebida por Leonel Brizola nas eleições de 1982 em toda a região metropolitana do Rio de Janeiro com dados ecológicos sobre o perfil dos eleitores desses municípios segundo o censo de 1980 (ibidem:280). Tal comparação importa não apenas porque Brizola era, 
naquela ocasião, o herdeiro autorreivindicado do petebismo, mas também porque o contexto político adverso o obrigara a reformular seu discurso trabalhista. Apelidado por Darcy Ribeiro de "Socialismo Moreno", este novo trabalhismo buscava, sobretudo, adaptar as premissas ideológicas do socialismo europeu às idiossincrasias da sociedade brasileira (Sento-Sé, 2004) e, em segundo plano, matizar o foco marxista na dominação de classes para incorporar ao discurso político a opressão sofrida pelos não brancos (Soares e Silva, 1985:256). Este discurso permitiu, dentre outras coisas, que o PDT mantivesse algum compromisso com o socialismo, mas incorporasse em suas listas eleitorais duas importantes lideranças de movimentos étnico-raciais: o líder indígena Mário Juruna e o militante histórico do movimento negro Abdias do Nascimento, ambos eleitos em 1982 para a Câmara dos Deputados Federais.

Comparando votação e dados contextuais, Soares e Silva concluem que há uma correlação relevante entre a preponderância de não brancos em municípios da região metropolitana e a vitória de Brizola nestes municípios (ibidem:269). Há que se destacar, contudo, que as limitações intrínsecas aos dados utilizados por Souza, Soares e Silva tornam tais conclusões tentativas, como os próprios autores reconhecem. Quando observamos os estudos mais recentes, porém, não é possível perceber uma confluência tão grande nas conclusões. Enquanto autores como Mônica Castro (1993), Reginaldo Prandi (1996) e Gladys Mitchell (2009) acreditam que não brancos permanecem tendo comportamento eleitoral específico, Elza Berquó e Luiz Felipe de Alencastro (1992) mostram limites dessa hipótese, enquanto Natália Bueno e Thad Dunning (2013) defendem que tal comportamento é demasiado residual.

Aplicando um conjunto de regressões logísticas a dados de um survey sobre opções eleitorais em cinco municípios de cinco unidades federativas distintas, Mônica Castro buscou estabelecer o peso relativo da raça de cada entrevistado no seu comportamento político. Além de levar em conta a suposta preferência dos não brancos por candidatos de esquerda e/ou mais "populistas", Castro levou em consideração também a proporção de eleitores que planejavam votar em branco ou nulo nas eleições do período. Ela conclui que embora "o contexto socioeconômico [seja] mais ou menos central" no comportamento eleitoral dos entrevistados, "o efeito raça é [...] ambíguo: pretos e pardos se alienam mais que os brancos, mas, quando decidem participar do processo eleitoral, escolhem em proporção relativamente maior os candidatos 
de esquerda" (1993:483). Porém, se ser não branco aumenta a probabilidade de um comportamento radicalista, isto está longe de implicar uma etnização do voto, pois implica também maior alienação eleitoral (ibidem:485).

Também trabalhando com os dados de um survey sobre as intenções de voto para presidente em 1994, realizado pelo Instituto Datafolha, Prandi assevera que houve nesse pleito uma "clara tendência do eleitorado preto e pardo para votar preferencialmente em Luiz Inácio Lula da Silva" (1996:12). Mesmo isolando variáveis como classe, escolaridade e idade, a vantagem de Lula da Silva aumenta nos estratos não brancos, enquanto Fernando Henrique Cardoso obtinha mais votos nos estratos brancos. Tal vantagem de Lula da Silva dentre os não brancos não é tão intensa em termos estatísticos, mas constante nos diferentes coortes analisados por Prandi. Por isto o autor não acredita que tal viés expresse um "voto étnico à esquerda", mas, sim, um voto de protesto, através do qual as populações negras "tenham tido, pelo voto em Lula, a possibilidade de expressar uma dimensão de sua identidade, na qual a exteriorização da discordância e o protesto têm um lugar importante" (ibidem:13).

Contudo, também trabalhando com dados de um levantamento do Instituto Datafolha, Elza Berquó e Luiz Felipe de Alencastro acreditam haver indícios fortes de emergência do voto étnico dentre os negros em São Paulo, sobretudo dentre "os mulatos de mais baixa escolaridade". Porém, eles não detectaram o mesmo comportamento no Espírito Santo, outro estado incluído no levantamento. Embora reconheçam que os dados dos dois estados são inconclusivos para avaliar a pervasividade do voto étnico em âmbito nacional, os autores creem haver uma tendência ao seu fortalecimento (1992:86).

Gladys Mitchell, por seu turno, desloca este debate em torno da existência de um viés ideológico no voto étnico ao focar na relação entre cor/raça autodeclarada do eleitor e sua preferência por candidatos negros. Para ela, tão importante quanto avaliar se não brancos preferem candidatos de esquerda ou de oposição é indagar se os subgrupos que compõem este agregado tendem a votar em negros. Por isto, ela se baseia em um survey com eleitores de diferentes bairros de Salvador e São Paulo em que eles eram questionados sobre sua identificação racial e se já haviam votado em candidatos negros. A partir desses dados, Mitchell conclui que 
à medida que as cores se tornam mais escuras, ou à medida que a identificação pela cor se move do branco ao negro no espectro das cores, aumenta a estimativa de probabilidade de que um afro-brasileiro em Salvador e São Paulo vote em um candidato negro (2009:294).

Segundo ela, tal propensão tende a aumentar à medida que esses "afro-brasileiros" sobem na hierarquia social e que se engajam mais fortemente à militância identitária (ibidem:301).

Todavia, um estudo bem mais recente parece se contrapor a essas previsões de fortalecimento do voto étnico. Utilizando diferentes métodos de pesquisa, Natália Bueno e Thad Dunning (2013) tentam determinar quais elementos melhor explicam a sub-representação política dos negros no Brasil. A partir da heteroclassificação das fotos de uma amostra com cinco mil candidatos a diferentes cargos nas eleições de 2010, os autores percebem que a ausência dos negros da política não pode ser atribuída exclusivamente a um viés no recrutamento das candidaturas (ibidem:6). Para testar em que medida eles são filtrados, então, pelas decisões dos eleitores, Bueno e Dunning realizam um complexo estudo experimental em que demandam a uma amostra de eleitores que escolham qual candidato mais votável em um programa eleitoral televisivo ficcional. As características dos candidatos fictícios são meticulosamente manipuladas com o objetivo de saber se candidatos não brancos têm menor apelo que os equivalentes brancos. Porém, os autores não perceberam com tal experimento nenhuma preferência significativa por candidatos brancos (ibidem:34). Ao que parece, o único viés estatisticamente relevante e capaz de explicar o que filtra os candidatos negros "pode estar na desigualdade de recursos entre políticos brancos e não brancos" (ibidem:47), já que os dados do TSE sugerem que "candidatos brancos recebem mais contribuições de campanha do que não brancos" (ibidem:45).

O trabalho de Bueno e Dunning é um dos poucos que tentam explicar a sub-representação dos negros de forma múltipla, recorrendo a diferentes tipos de pesquisa para testar hipóteses distintas. Contudo, as dificuldades do experimento desenhado pelos autores e, sobretudo, a opção pela amostragem os impedem de perceber o papel que as dinâmicas partidárias podem ter na sub-representação dos negros na política. Vale notar que a própria distribuição desigual de recursos de campanhas, apontada por Bueno e Dunning como possível variável 
explicativa, sugere que as dinâmicas intra e interpartidárias podem ter grande relevância na sub-representação dos negros na política.

De modo geral, um problema desta literatura é o fato de ela focar mais na verificação de um viés étnico na demanda dos eleitores do que na oferta de candidaturas. Como vários autores têm sugerido, parece haver não apenas uma orientação ideológica no comportamento eleitoral dos pretos e pardos, mas também uma maior abertura de determinados partidos às candidaturas destes grupos. Cloves Oliveira percebeu, em uma pesquisa sobre as eleições para vereadores em Salvador, uma preponderância de candidatos negros nos partidos de esquerda e mais identificados com o trabalhismo (1991:98). A partir de entrevistas com dirigentes políticos, Meneguello, Mano e Gorski (2012) destacam não apenas a maior centralidade que partidos de esquerda dão à presença de negros em suas listas, mas também a maior facilidade que eles têm em recrutar estes contingentes nos movimentos sociais.

Logo, é preciso avaliar de forma mais sistemática a existência de um viés racial no recrutamento de candidaturas pelos partidos nacionais, sobretudo porque as dinâmicas partidárias parecem ter grande peso na sub-representação política de grupos. Sem excluir de antemão a existência de vieses raciais nas escolhas dos eleitores, o objetivo deste artigo é avaliar em que medida há um viés racial no modo como o sistema partidário brasileiro lida com as candidaturas em nível municipal. Isto envolve não apenas uma investigação em torno da maior ou menor proporção de candidatos não brancos, como fazem Bueno e Dunning (2013), mas também uma avaliação da distribuição destes candidatos em diferentes legendas, com chances maiores ou menores de sucesso eleitoral. Investigar esta dimensão é importante, aliás, para determinar em que medida há uma maior sensibilidade para a questão racial nos partidos ditos de esquerda ou socialistas.

\section{METODOLOGIA}

O principal obstáculo para as pesquisas sobre raça e eleições municipais está na ausência de dados sobre a cor autodeclarada dos candidatos e políticos brasileiros. Ao contrário do que ocorre com a variável gênero, devidamente indexada nos arquivos do TSE, a cor dos candidatos não era computada nos registros eleitorais até 2014, ano em que o TSE passou a exigir dos candidatos registrados nas eleições que declarassem sua raça/cor. Por conta disto, as pesquisas sobre raça e eleições 
feitas antes de 2014 foram obrigadas a "produzir" este dado. Normalmente, existem três opções mais comuns: a heteroclassificação, a autoclassificação e métodos mistos.

Em pesquisas como as feitas por Meneguello, Mano e Gorski (2012), opta-se pela cor autodeclarada pelos políticos. Nestes casos, os pesquisadores costumam entrar em contato diretamente com os políticos incluídos no recorte e os questionam sobre como eles se classificam. Como todos os outros, este método apresenta vantagens e desvantagens. A principal vantagem é respeitar as normatizações internacionais que recomendam a autoclassificação como meio de delineamento de fronteiras identitárias, já que isto viabiliza pesquisas sobre pertencimentos grupais sem desconsiderar a autonomia dos indivíduos. Ademais, a autoclassificação torna os levantamentos sobre os políticos comparáveis aos dados produzidos pelo IBGE, que também adota a autoclassificação.

Por outro lado, a autoclassificação tem problemas. Em primeiro lugar, quase nunca é possível obter informações sobre todos os políticos incluídos em um determinado recorte dadas as dificuldades de acesso a este grupo. Em segundo lugar, é preciso lembrar também que muitos políticos se recusam a responder tal questão. Embora as pesquisas do IBGE tenham de lidar também com recusas deste tipo, elas adquirem outro significado nas pesquisas com políticos. A politização da questão racial no Brasil tem criado resistências em alguns setores políticos, por isto seus membros costumam se recusar a adotar uma dada distinção racial.

Uma alternativa intermediária é recorrer às burocracias dos partidos ou das instituições estatais em busca de dados secundários, como faz Oliveira (1991). Não obstante esta estratégia contorne as dificuldades de acessar determinados políticos, ou mesmo suas resistências pessoais, ela coloca todos os problemas relativos à arbitrariedade dos dados fornecidos, que dificilmente podem ter sua validade testada.

Diante disto, uma alternativa cada vez mais utilizada é a heteroclassificação, em que fotos dos candidatos são submetidas à avaliação de outras pessoas (Bueno e Dunning, 2013). Por razões evidentes, tal método suscita inúmeros problemas. Além de questões éticas (nem sempre alguém classificado como branco se enxerga como branco), existe toda uma série de problemas relacionados à comparação com os dados levantados pelo IBGE. Ademais, em um país com classificações raciais 
fluidas, é difícil crer que a heteroclassificação forneça dados estáveis e válidos.

Apesar disso, a heteroclassificação apresenta vantagens importantes. Em primeiro lugar, ela capta como determinados políticos tendem a ser classificados pelos outros. Para muitos dos fins desta pesquisa, importa mais saber se determinados indivíduos têm menos chances de ascensão política por serem tendencialmente vistos como pretos e pardos. Se entendemos que raça é um conceito sociológico e não biológico (Guimarães, 2003), percebemos que pretos e pardos não são aqueles que possuem supostas marcas objetivas de negritude, mas quem tende a ser classificado como tal pelos outros por conta dessas marcas. Logo, tanto dados baseados na autodeclaração quanto na heteroclassificação podem ser criticados metodologicamente. Em segundo lugar, vários estudos têm atestado que é alta a correlação entre a maneira como as pessoas autodeclaram sua cor e o modo como são percebidas pelos outros (Silva, 1999; Muniz, 2012; Prandi, 1996), relativizando a tese de que nossas categorias de classificação racial seriam arbitrárias ou fluidas demais. Em terceiro lugar, mesmo que concordemos que há uma grande fluidez no nosso modelo classificatório, ela pode ser contornada pela adoção de uma heteroclassificação múltipla, em que várias pessoas classificam as mesmas fotos.

Neste artigo, a cor dos candidatos a vereador em 2012 na cidade do Rio de Janeiro e em São Paulo foi aferida por uma equipe de classificadores. Para simplificar a atribuição, as fotos deveriam ser classificadas a partir das três principais categorias empregadas pelo IBGE (branco, pardo e preto) $)^{5}$. Para facilitar a visualização dos dados, os candidatos classificados como pardos ou pretos foram congregados na categoria "não brancos".

As 2.733 fotos dos candidatos foram extraídas do site do $\mathrm{TSE}^{6}$, sendo que, dentre elas, 1.596 são de candidatos a vereador no Rio de Janeiro e 1.137 em São Paulo. Todas elas foram classificadas por quatro pesquisadores. Ainda que a origem social e profissional comum destes classificadores possa sugerir um "viés classificatório", é fundamental frisar que não é nossa pretensão estabelecer "objetivamente" a cor dos candidatos. A validade da heteroclassificação múltipla tem de ser avaliada pragmaticamente, isto é, se o modo como os candidatos foram classificados acompanhar desigualdades estatisticamente relevantes, isto, por si só, já sugere que tais classificações indicam alguma desigualdade socialmente relevante. Noutros termos, embora não saibamos se 
aqueles que foram classificados pela equipe como preto ou pardo são classificados assim também pela sociedade, o fato de eles serem vítimas de desigualdades sociais e políticas já sugere que nossas classificações não são tão arbitrárias.

Finalmente, é preciso destacar a alta concordância entre os classificadores envolvidos. De acordo com a Tabela 1, os quatro classificadores concordaram com a cor do candidato em mais da metade das fotos $(62,9 \%)$ e em $25 \%$ do universo houve uma alta taxa de concordância (apenas um classificador optou por uma cor diferente dos outros três). As discordâncias equilibradas atingiram apenas 12,1\% do universo. Note-se também que não houve nenhuma coincidência das categorias polares, já que nenhum candidato foi classificado como preto e branco ao mesmo tempo por dois classificadores. Como os casos de empate foram poucos, todos eles foram submetidos a um quinto classificador, incumbido de desempatar a classificação.

Tabela 1

Concordâncias entre as Classificações Binárias

(Branco e Não Branco)

\begin{tabular}{l|c|c}
\hline & N & \% \\
\hline Concordância total $(4 \times 0)$ & 1.718 & 62,9 \\
Concordância alta $(3 \times 1)$ & 683 & 25 \\
Concordância baixa $(2 \times 2)$ & 332 & 12,1 \\
\hline Total & $\mathbf{2 . 7 3 3}$ & $\mathbf{1 0 0}$ \\
\hline
\end{tabular}

Fonte: O autor, a partir de dados do TSE.

\section{RESULTADOS}

O Gráfico 1 nos permite comparar a distribuição de cada um dos grupos de cor na população de cada município, nas candidaturas ofertadas pelo conjunto de partidos que participou do pleito municipal de 2012 e dentre os eleitos nesses pleitos. É possível perceber que tanto na cidade do Rio de Janeiro quanto no município de São Paulo, não há uma grande distância entre a proporção de não brancos na população total e a proporção de não brancos nas candidaturas. De acordo com o censo de 2010, o Rio de Janeiro possuía 48\% de não brancos e São Paulo $37,1 \%$. Em 2012, a proporção de candidatos não brancos foi de $37,8 \%$ no Rio e 31,6\% em São Paulo. A diferença é menor em São Paulo, mas, ainda assim, não é tão significativa no Rio de Janeiro. De certo modo, este dado é corroborado pela pesquisa de Bueno e Dunning (2013), que a 


\section{Gráfico 1}

Distribuição dos Grupos de Cor* na População dos Municípios, Candidaturas e Eleitos** para Vereador em 2012

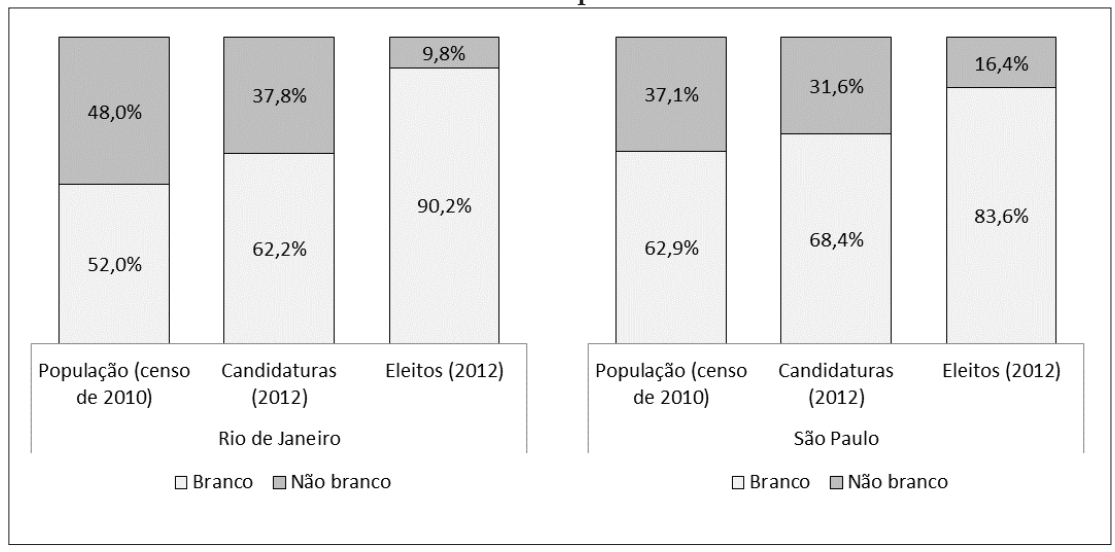

Fonte: O autor, a partir de dados do TSE.

* Ao calcular a proporção de cada grupo de cor na população dos municípios, consideramos como "brancos" todos os autodeclarados brancos e amarelos; e "não brancos" todos os autodeclarados pretos, pardos e indígenas.

** Os eleitos englobam todos os candidatos eleitos por média ou por quociente eleitoral em dezembro de 2013

partir de uma metodologia semelhante à empregada aqui chegaram à mesma conclusão.

Por outro lado, quando comparamos a proporção de não brancos nas candidaturas com a proporção de não brancos eleitos, o cenário muda. Os $37,8 \%$ de candidatos não brancos do Rio de Janeiro transformam-se em apenas 9,8\% de eleitos. Embora menor, a discrepância em São Paulo ainda é grande, já que os $31,6 \%$ de candidatos não brancos conseguiram ocupar apenas 16,4\% das cadeiras da Câmara de Vereadores. Ao que parece, o principal filtro que afasta os não brancos da representação não está propriamente na oferta de candidaturas, mas, sobretudo, nas chances eleitorais. Porém, este dado deve ser lido com cautela. As câmaras de vereadores dos dois municípios são muito pequenas e dificultam qualquer generalização estatística; ademais, estamos trabalhando apenas com os dados de uma eleição. Entender melhor a seletividade eleitoral dependeria de uma série histórica maior, que permitisse entender até que ponto as chances eleitorais de brancos e não brancos permanecem constantes no tempo.

No entanto, ainda que a proporção de não brancos nas candidaturas não esteja muito distante da proporção deste grupo na população de 
cada município, um fator importante é a desigualdade na distribuição deste grupo pelas listas dos diferentes partidos. Os Gráficos 2 e 3 mostram o percentual de brancos e não brancos nas listas de cada partido no Rio de Janeiro e em São Paulo, respectivamente.

É possível notar que a participação de brancos nestas listas oscila bastante. No Rio, partidos como o PMDB lançaram mais de $80 \%$ de candidatos classificados como brancos, enquanto o PPL lançou mais de $60 \%$ de candidatos não brancos. Em São Paulo, o campeão de candidaturas brancas foi o PSDB (86\%), enquanto o PRB foi o que mais lançou candidatos não brancos (53\%).

De modo impressionista, já é possível detectar algumas tendências presentes nos Gráficos 2 e 3 . Em primeiro lugar, os partidos tradicionalmente classificados à esquerda do espectro político parecem lançar mais candidatos não brancos nos dois municípios do que os partidos de direita. $\mathrm{O}$ mesmo acontece quando consideramos a distinção entre partidos grandes, com expressão nacional homogênea, de um lado, e partidos pequenos, com expressão local mais forte. Ao que parece, estes últimos tendem também a lançar mais candidatos não brancos do que brancos.

A divisão dos partidos no espectro esquerda e direita sempre suscita controvérsia. Isto ocorre não apenas porque a definição do que é esquerda e direita se modificou bastante no decorrer da história, mas também porque tal distinção busca dividir em categorias discretas uma dimensão ideológica contínua. Portanto, trata-se de uma distinção ideal-típica que sempre refletirá algum grau de exagero, unilateralidade e arbitrariedade. Levando em conta as divisões já clássicas de Novaes (1994) e Kinzo (1993) e as ponderações mais recentes de Carreirão (2006), Miguel e Machado (2007), propomos uma divisão própria. Nesta, foram considerados como partidos de esquerda PT, PCdoB, PSOL, PHS, PDT, PSB, PMN, PSTU, PCB e PCO; de centro PMDB, PSDB, PV e PPS; e de direita DEM, PTB, PTN, PSDC, PRB, PTdoB, PSD, PR, PP, PRTB, PRP, PTC, PSC, PSL e PPL. Diante disso, o Gráfico 4 mostra a distribuição de brancos e não brancos em cada um desses agregados ideológicos.

Como é possível perceber, não há uma grande distância na distribuição de candidatos por cor quando agregamos os dados de acordo com a distinção esquerda-centro-direita. Nos dois municípios, a maior abertura aos não brancos em partidos de esquerda como PCdoB, PMN, 


\section{Gráfico 2}

Candidaturas do Rio de Janeiro de acordo com a Cor por Partido Político*

\begin{tabular}{|c|c|}
\hline PMDB & $81 \%$ \\
\hline DEM & $75 \%$ \\
\hline PV & $75 \%$ \\
\hline PSDB & $74 \%$ \\
\hline PTN & $70 \%$ \\
\hline PPS & $68 \%$ \\
\hline $\mathrm{PP}$ & $67 \%$ \\
\hline PIC & $65 \%$ \\
\hline PSB & $65 \%$ \\
\hline PT & $65 \%$ \\
\hline PSOL & $64 \%$ \\
\hline PSD & $63 \%$ \\
\hline PSC & $61 \%$ \\
\hline $\mathrm{PC}$ do B & $59 \%$ \\
\hline PTB & $59 \%$ \\
\hline PDT & $58 \%$ \\
\hline PSDC & $56 \%$ \\
\hline PT do B & $56 \%$ \\
\hline PSL & $55 \%$ \\
\hline PHS & $53 \%$ \\
\hline PRTB & $52 \%$ \\
\hline PR & $49 \%$ \\
\hline PRB & $49 \%$ \\
\hline PRP & $48 \%$ \\
\hline PMN & $47 \%$ \\
\hline PPL & $36 \%$ \\
\hline TOTAL & $62 \%$ \\
\hline
\end{tabular}

Fonte: $\mathrm{O}$ autor, a partir de dados do TSE.

* Para facilitar a exposição, excluímos desta lista os partidos que lançaram menos de dez candidatos. São eles: PSTU, PCO e PCB. 
Socialismo Moreno, Conservadorismo Pálido?

\section{Gráfico 3}

Candidaturas de São Paulo de acordo com a Cor por Partido Político*

\begin{tabular}{|c|c|c|}
\hline PSDB & $86 \%$ & $14 \%$ \\
\hline PMDB & $85 \%$ & $15 \%$ \\
\hline DEM & $83 \%$ & $17 \%$ \\
\hline PR & $80 \%$ & $20 \%$ \\
\hline PPS & $78 \%$ & $22 \%$ \\
\hline PTN & $76 \%$ & $24 \%$ \\
\hline PSD & $76 \%$ & $24 \%$ \\
\hline PV & $74 \%$ & $26 \%$ \\
\hline PSL & $73 \%$ & $27 \%$ \\
\hline PP & $73 \%$ & $27 \%$ \\
\hline PTC & $71 \%$ & $29 \%$ \\
\hline PSOL & $71 \%$ & $29 \%$ \\
\hline PTB & $70 \%$ & $30 \%$ \\
\hline PPL & $67 \%$ & $33 \%$ \\
\hline PSB & $67 \%$ & $33 \%$ \\
\hline PRTB & $67 \%$ & $33 \%$ \\
\hline PRP & $64 \%$ & $36 \%$ \\
\hline PT & $64 \%$ & $36 \%$ \\
\hline PDT & $63 \%$ & $37 \%$ \\
\hline PHS & $63 \%$ & $37 \%$ \\
\hline PMN & $63 \%$ & $38 \%$ \\
\hline PT do B & $62 \%$ & $38 \%$ \\
\hline PC do B & $53 \%$ & \\
\hline PSC & $52 \%$ & \\
\hline PSDC & $51 \%$ & \\
\hline PRB & $47 \%$ & \\
\hline TOTAL & $68 \%$ & $32 \%$ \\
\hline
\end{tabular}

$\square$ Branco $\square$ Não branco

Fonte: o autor, a partir de dados do TSE.

* Para facilitar a exposição, excluímos dessa lista os partidos que lançaram menos de dez candidatos. São eles: PSTU, PCO e PCB. 


\section{Gráfico 4}

Distribuição dos Grupos de Cor nas Candidaturas de acordo com a Posição Ideológica do Partido

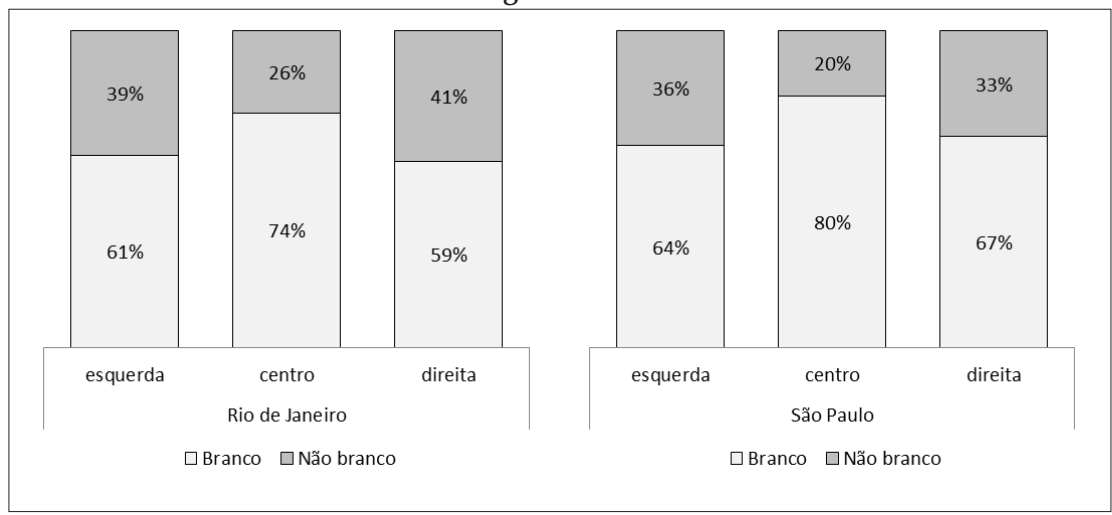

Fonte: $\mathrm{O}$ autor, a partir de dados do TSE.

PDT e PT é compensada pelo fato de muitos partidos pequenos de direita como PRB, PSDC, PSC etc. também lançarem muitos candidatos não brancos. Logo, ao menos do ponto de vista das candidaturas, não é possível dizer que a esquerda confere no agregado mais espaço aos não brancos em suas listas. Além disto, chama a atenção a sobrerrepresentação de não brancos nos partidos classificados aqui como de centro. As listas de partidos como PMDB, PSDB, PPS e PV foram dominadas por brancos, já que no Rio de Janeiro $74 \%$ dos candidatos lançados pelos quatro foram classificados como brancos, e em São Paulo, $80 \%$.

Tudo isto permite colocar em xeque a tese segundo a qual partidos de esquerda tendem a ser mais abertos a não brancos do que a partidos de direita. Embora legendas como PCdoB, PT, PDT etc. de fato lancem mais candidatos não brancos que seus principais concorrentes, esta tendência parece ser contrabalançada pelo fato de partidos de direita pequenos também o fazerem, o que confirma uma tendência presente nas últimas eleições nacionais em 2014 (cf. Campos e Machado, 2015c).

Assim, é preciso investigar em que medida a distribuição dos candidatos de acordo com a cor não obedece a outra importante clivagem partidária: o tamanho das legendas. Esta variável parece importante na medida em que é de se esperar que partidos com menor capital político (com menos recursos, menos candidatos eleitos, mais jovens, menos votos etc.) tenham menos liberdade de escolha ou capacidade de atração de candidatos. Por isto, à exceção de partidos com alto rigor disciplinar e ideológico, é possível supor que partidos pequenos tendam a 
estratégias de recrutamento mais próximas do catch all. Ao dividir os partidos em grandes, médios e pequenos, é preciso levar em conta que a variável tamanho é eminentemente política e tem a ver com os recursos capazes de serem mobilizados pelo partido na luta política.

Considerando o número de filiados declarados por partido em $2012^{7}$, a bancada conquistada na Câmara dos Deputados Federais e a votação obtida nas eleições de 2012, os partidos foram divididos em três grupos: partidos grandes (PMDB, PT, DEM e PSDB), partidos médios (PDT, PTB, PP, PR, PSB, PPS, PCdoB, PV, PRB e PSD) e partidos pequenos (PRP, PMN, PSOL, PSL, PSC, PTC, PTdoB, PSDC, PHS, PTN, PRTB, PCB, PPL, PSTU e PCO).

Conforme demonstrado no Gráfico 5, parece haver uma associação entre tamanho do partido e presença de não brancos nas listas; tal associação é presente nos dois municípios, porém mais forte no Rio de Janeiro. Como sugerido pela hipótese discutida anteriormente, partidos grandes parecem menos abertos à candidatura de não brancos, enquanto as legendas menores se comportam de modo oposto. Uma hipótese explicativa para isto é que as listas dos partidos menores tendem a refletir de modo mais próximo a oferta demográfica de lideranças dispostas a se candidatar. Partidos maiores, por seu turno, têm de lidar com uma distribuição predefinida de capital político, o que torna suas elites menos abertas a grupos tradicionalmente marginalizados da política, como não brancos e mulheres.

\section{Gráfico 5}

Distribuição dos Grupos de Cor nas Candidaturas de acordo com o Tamanho do Partido (Critério Nacional)

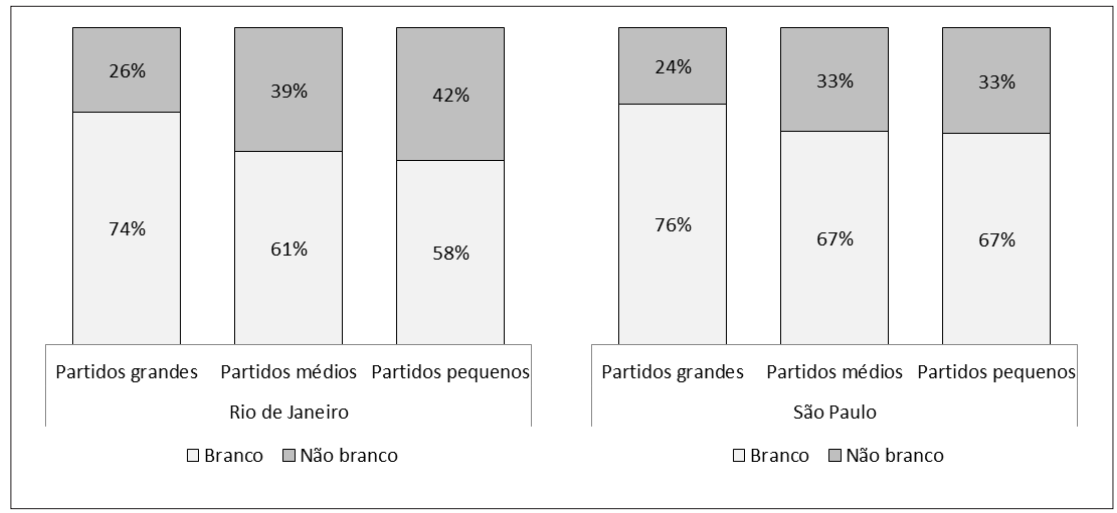

Fonte: O autor, a partir de dados do TSE. 
Pode-se objetar, no entanto, que a divisão entre partidos pequenos, médios e grandes não faz jus às dinâmicas da política local. Um partido como o PV foi considerado como "médio" na análise anterior, embora costume ser importante na política carioca. De fato, nem sempre a importância local de um dado partido reflete sua expressividade nacional. Para contornar essas críticas e reconsiderar o vínculo entre tamanho do partido e a presença de não brancos em suas listas, optou-se por utilizar como índice a votação média, recebida por partido, nas últimas três eleições $(2004$, 2008 e 2012) em cada uma das capitais consideradas pelo estudo. É importante considerar mais de uma eleição para se ter uma ideia mais acurada da relevância de cada partido no tempo. No caso dos partidos novos, que não existiam em alguma das eleições consideradas, levamos em conta apenas os pleitos em que eles efetivamente participaram.

Para o Rio de Janeiro, consideramos como "partidos grandes" aqueles que obtiveram mais de $5 \%$ dos votos totais em média nas três eleições; "partidos médios" os que obtiveram entre $2 \%$ e $4,9 \%$; e "partidos pequenos" todos os que receberam em média menos do que $2 \%$ dos votos. Com esses critérios, os partidos grandes englobam DEM, PMDB, PT, PSDB e PDT; os médios abrangem PSOL, PR, PSC, PRB, PP, PV, PTdoB, PTB, PSB, PSDC, PCdoB, PPS e PSD; e os pequenos incluem PRTB, PTC, PSL, PHS, PTN, PMN, PSTU, PRP, PCB, PPLe PCO. Em São Paulo, incluímos no rol dos partidos grandes todos aqueles que receberam em média mais de 4,5\% dos votos nas eleições (PT, PSDB, PSD, DEM, PV, PTB e PMDB); o agregado dos partidos médios abrange aqueles que obtiveram menos de $4,4 \%$ e mais $1 \%$ em média (PR, PP, PPS, PRB, PSB, PDT, PCdoB, PSOL e PSC); e dentro do grupo de partidos pequenos estão todos os que receberam em média menos de $1 \%$ dos votos da cidade (PHS, PTN, PSL, PRP, PMN, PPL, PTdoB, PSDC, PSTU, PTC, PRTB, PCB e PCO). O Gráfico 6 mostra a distribuição dos brancos e não brancos nesses agregados que se basearam na votação média dos partidos em cada uma das cidades.

A comparação do Gráfico 6 com o Gráfico 5 evidencia que a mudança de critério não refuta a hipótese anteriormente levantada, qual seja, a de que partidos grandes dão menos espaço para candidatos não brancos. Esta tendência permanece quase inalterada nos dois gráficos, sendo que a única exceção são os partidos agora classificados como pequenos em São Paulo de acordo com o critério da votação média nas últimas eleições. 


\section{Gráfico 6}

Distribuição dos Grupos de Cor nas Candidaturas de acordo com o

Tamanho do Partido

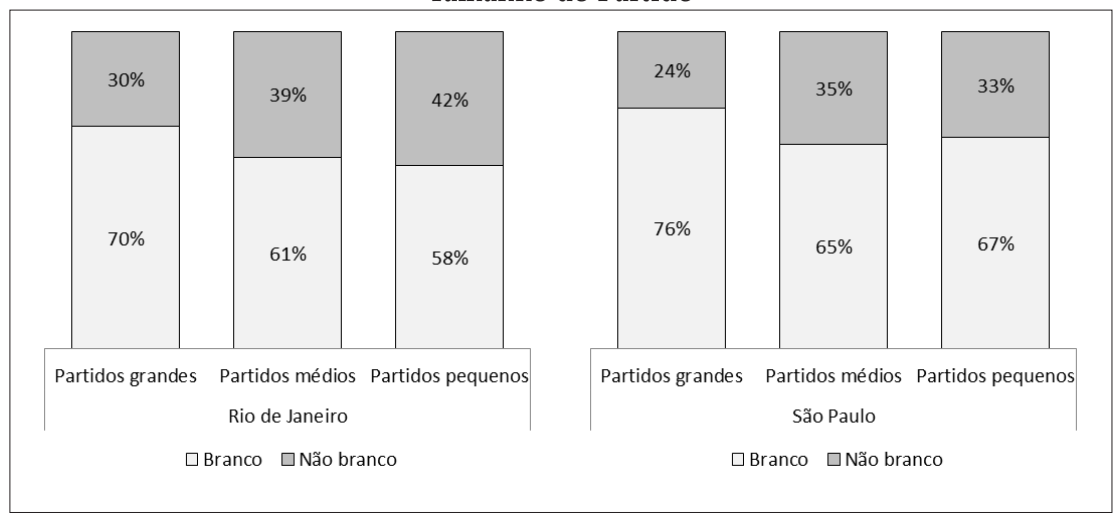

Fonte: $\mathrm{O}$ autor, a partir de dados do TSE.

\section{CONCLUSÕES}

De diferentes pontos de vista, a sub-representação dos pretos e pardos é um traço injusto e antidemocrático da política brasileira. Contudo, é particularmente difícil pensar em políticas que solucionem este problema se ainda não há diagnósticos sobre os motivos que excluem os não brancos da política. A bibliografia sobre a relação entre raça e eleições contribui pouco para solucionar este dilema na medida em que foca na existência ou não de uma orientação étnica nas votações, por um lado, e na sub-representação política basicamente no âmbito federal, por outro.

O foco nas demandas dos eleitores também relegou a um segundo plano o problema da oferta de candidaturas. Como algumas pesquisas sobre a ausência de mulheres na política vêm apontando, a oferta de candidatas parece influenciar mais a sub-representação feminina no Parlamento do que um viés sexista do eleitor, embora este não possa ser totalmente desconsiderado (Miguel e Queiroz, 2006). Tudo isto justifica investigações sobre a oferta de candidatos não brancos pelos partidos brasileiros.

Por outro lado, os dados discutidos mostram que a sub-representação dos não brancos não pode ser atribuída somente à carência de candidatos na oferta agregada das listas partidárias. Corroborando os achados de Bueno e Dunning (2013) e de Campos e Machado (2015c), o déficit de representação descritiva é relativamente pequeno quando compa- 
ramos o total de não brancos lançados candidatos em 2012 e o total de não brancos na população de cada um dos municípios analisados. Todavia, ao observar a distribuição destas candidaturas nos partidos, é possível notar desigualdades importantes que talvez expliquem as menores chances eleitorais dos pretos e pardos.

Ao contrário do que grande parte da bibliografia especializada sugere, não houve, em 2012, uma maior abertura dos partidos de esquerda a candidatos não brancos do que os partidos de direita. Embora legendas como PT, PCdoB e PDT de fato recrutem mais candidatos não brancos, o mesmo vale para partidos pequenos de direita. Curiosamente, os partidos com uma proporção maior de brancos se concentram no centro do espectro político. Ao que parece, o viés racial do recrutamento de candidaturas não varia propriamente de acordo com a cor ideológica do partido, mas, sim, com o seu tamanho e relevância política. Partidos grandes e estabelecidos no campo político tendem a conferir menos espaço para candidatos não brancos do que partidos pequenos. Excetuando-se alguns casos, é possível supor que os partidos pequenos têm de recrutar suas lideranças em estratos sociais mais baixos, $\mathrm{o}$ que aumenta a probabilidade de que não brancos sejam recrutados ${ }^{8}$.

Não foi o objetivo aqui estabelecer quais fatores excluem os não brancos das listas partidárias, nem determinar em que medida tal exclusão pode ser atribuída às desigualdades de classe, educação formal, capital político etc. ${ }^{9}$ Mas, para além das restrições do foco deste artigo, é preciso destacar o modo desigual como os não brancos se distribuem pelas legendas. Partidos com maior chance de sucesso eleitoral nos municípios estudados, como PMDB e PSDB, costumam ser justamente os que dão menos espaço a esse grupo em suas listas. Isto sugere que uma diretriz que equalizasse a oferta de candidatos não brancos em todos os partidos talvez já conseguisse efeitos benéficos importantes sem, contudo, demandar uma polêmica e complexa modificação do nosso modelo de escolha dos candidatos.

(Recebido para publicação em agosto de 2014) (Aprovado para publicação em dezembro de 2014) 


\section{NOTAS}

1. O inteiro teor da proposta pode ser consultado em <http://www.camara.gov. br/ proposicoesWeb / fichadetramitacao?idProposicao=529275>.

2. As eleições de 2014 serão as primeiras em que o TSE computou a cor/raça autodeclarada dos candidatos registrados. No entanto, não existem dados disponíveis sobre as eleições pretéritas e, ao menos até 2016, não existem dados sobre as eleições municipais.

3. Cf. <http://censo2010.ibge.gov.br/apps/atlas/>.

4. O Laeser utiliza tradicionalmente a heteroclassificação das fotos dos parlamentares, enquanto a ONG Unegro opta pela autoclassificação. Já Johnson III (1998) não deixa claro qual método utilizou.

5. Foram ignoradas as categorias "amarelo" e "indígena", as quais costumam congregar menos de $2 \%$ da população das regiões pesquisadas.

6. Trabalhamos apenas com as candidaturas deferidas em 26 de dezembro de 2013.

7. Ver <http://www.tse.jus.br/eleicoes/estatisticas/filiados>.

8. Para suprimir essa lacuna, seria de grande valia a realização de pesquisas sobre a situação dos pretos e pardos em alguns partidos políticos. Sobre a relação de determinados partidos com os políticos não brancos, cf. Valente (1986), Santos (1992) e Soares (2009).

9. Uma discussão sobre os fatores que mais impactam nas chances eleitorais dos pretos e pardos pode ser encontrada em Campos e Machado (2015b). 


\section{REFERÊNCIAS BIBLIOGRÁFICAS}

BERQUÓ, Elza; ALENCASTRO, Luiz Felipe de. (1992), “A Emergência do Voto Negro”. Novos Estudos, vol. 33, pp. 77-88.

BRAGA, Izabel. (2013), “Congresso Estuda Implementar Cota para Parlamentares Negros". O Globo, 30 de outubro.

BUENO, Natália; DUNNING, Thad. (2013), Race, Resources, and Representation: Evidence from Brazilian Politicians. Palestra ministrada no seminário Race, class, and representation: evidence from Brazilian politicians. Faculdade de Filosofia, Letras e Ciências Humanas, Universidade de São Paulo, 17 de outubro. Disponível em http://www.fflch.usp.br/dcp/assets/docs/PDF/Bueno_and_Dunning_USP_ October_2013_v1.pdf.

CAMPOS, Luiz Augusto; MACHADO, Carlos. (2015a), “A Cor e o Sexo da Política: Composição das Câmaras Federais e Estaduais (2014)". Textos para Discussão do GEMAA, no 7, pp. 1-21.

_ (2015b), “A Raça dos (In)Eleitos”. Insight Inteligência, no 67, pp. 60-72.

. (2015c), “A Cor dos Eleitos: Determinantes das Chances Eleitorais dos Negros no Brasil". Revista Brasileira de Ciência Política, no 16, pp. 121-151.

CARDOSO, Daiene. (2013), “CCJ da Câmara Aprova Proposta de Cota para Parlamentar de Origem Negra". O Estado de S. Paulo, 30 de outubro.

CARREIRÃO, Yan de Souza. (2006), “Ideologia e Partidos Políticos: Um Estudo sobre Coligações em Santa Catarina”. Opinião Pública, vol. 12, pp. 136-163.

CASTRO, Mônica Mata Machado de. (1993), “Raça e Comportamento Político”. DADOS - Revista de Ciências Sociais, vol. 36, no 3, pp. 469-491.

FALCÃO, Márcio. (2013), “Comissão da Câmara Aprova Cota para Parlamentares Negros nos Legislativos". Folha de S. Paulo, 30 de outubro.

GUIMARÃES, Antonio Sérgio. (2003), “Como Trabalhar com 'Raça' em Sociologia”. Educação e Pesquisa, vol. 29, pp. 93-107.

HTUN, Mala. (2004), "Is Gender like Ethnicity? The Political Representation of Identity Groups". Perspectives on Politics, vol. 2, no 3, pp. 439-458.

JOHNSON III, Ollie. (1998), “Racial Representation and Brazilian Politics: Black Members of the National Congress, 1983-1999". Journal of Interamerican Studies and World Affairs, vol. 40, no 4, pp. 97-118.

KINZO, Maria D’Alva. (1993), Radiografia do Quadro Partidário Brasileiro. São Paulo, Konrad-Adenauer Stiftung.

KYMLICKA, Will. (1995), Multicultural Citizenship: A Liberal Theory of Minority Rights. Oxford e New York, Clarendon Press e Oxford University Press.

MAGNOLI, Demétrio. (2013), “O Brasil e a 'Nação Diaspórica'”. O Globo, 11 de novembro.

MANSBRIDGE, Jane. (1999), "Should Blacks Represent Blacks and Women Represent Women? A Contingent 'Yes'”. The Journal of Politics, vol. 61, no 3, pp. 628-657. 
MENEGUELLO, Rachel; MANO, Maíra Kubik; GORSKI, Caroline. (2012), “Alguns Condicionantes do Déficit Representativo de Mulheres e Negros na Política", in R. Meneguello et al. (orgs.), Mulheres e Negros na Política: Estudo Exploratório sobre o Desempenho Eleitoral em Quatro Estados Brasileiros. Campinas, Centro de Estudos de Opinião Pública, pp. 5-66.

MIGUEL, Luis Felipe. (2000), “Teoria Política Feminista e Liberalismo: O Caso das Cotas de Representação". Revista Brasileira de Ciências Sociais, vol. 15, no 44, pp. 91-102.

; MACHADO, Carlos. (2007), “Um Equilíbrio Delicado: A Dinâmica das Coligações do PT em Eleições Municipais (2000 e 2004)". DADOS - Revista de Ciências Sociais, vol. 50, no 4, pp. 757-793.

MIGUEL, Luis Felipe; QUEIROZ, Cristina Monteiro de. (2006), “Diferenças Regionais e o Êxito Relativo de Mulheres em Eleições Municipais no Brasil". Revista Estudos Feministas, vol. 14, pp. 363-385.

MITCHELL, Gladys. (2009), "Identidade Coletiva Negra e Escolha Eleitoral no Brasil”. Opinião Pública, vol. 15, pp. 273-305.

MUNIZ, Jerônimo O. (2012), “Preto no Branco?: Mensuração, Relevância e Concordância Classificatória no País da Incerteza Racial". DADOS - Revista de Ciências Sociais, vol. 55, no 1, pp. 251-282.

NORRIS, Pippa. (1997), Passages to Power: Legislative Recruitment in Advanced Democracies. Cambridge, Cambridge University Press.

; LOVENDUSKI, Joni. (1995), Political Recruitment: Gender, Race and Class in the British Parliament. Cambridge, Cambridge University Press.

NOVAES, Carlos Alberto Marques. (1994), “Dinâmica Institucional de Representação: Individualismo e Partidos na Câmara dos Deputados". Novos Estudos, no 38, pp. 99-147.

OLIVEIRA, Cloves Luiz Pereira. (1991), “O Negro e o Poder: Os Negros Candidatos a Vereador em Salvador, em 1988". Caderno CRH, Suplemento, pp. 94-116.

. (2002), “O Negro e o Poder no Brasil: Uma Proposta de Agenda de Pesquisa". Caderno $C R H$, no 36, pp. 49-67.

PAIXÃO, Marcelo; CARVANO, Luiz (eds.). (2008), Relatório Desigualdades Raciais (2007-2008). Rio de Janeiro, Garamond.

PERISSINOTTO, Renato; MIRÍADE, Angel. (2009), “Caminhos para o Parlamento: Candidatos e Eleitos nas Eleições para Deputado Federal em 2006". DADOS - Revista de Ciências Sociais, vol. 52, no 2, pp. 301-333.

PHILLIPS, Anne. (1991), Engendering Democracy. Pennsylvania, Pennsylvania State University Press.

. (1995), The Politics of Presence. New York, Oxford University Press.

. (2007), Multiculturalism without Culture. Princeton, Princeton University Press.

PITKIN, Hanna Fenichel. (1967), The Concept of Representation. Berkeley, University of California Press.

PRANDI, Reginaldo. (1996), "Raça e Voto na Eleição Presidencial de 1994". Estudos Afro-Asiaticos, no 30, pp. 61-78. 
SANTOS, Gevanilda Gomes. (1992), Partidos Políticos e Etnia Negra. Dissertação de mestrado, Pontifícia Universidade Católica de São Paulo, São Paulo.

SENTO-SÉ, João Trajano. (2004), “As Várias Cores do Socialismo Moreno”. Anos 90, vol. 11, no 19/20, pp. 49-76.

SILVA, Nelson do Valle. (1999), “Uma Nota sobre ‘Raça Social' no Brasil”, in C. Hasenbalg; N. do V. Silva; M. Lima (orgs.), Cor e Estratificação Social. Rio de Janeiro, Contracapa, pp. 107-123.

SOARES, Claudete. (2009), Raça, Classe e Cidadania: A Trajetória do Debate Racial no Partido dos Trabalhadores (1980-2003). Tese de doutorado, Universidade Estadual de Campinas.

SOARES, Gláucio Ary Dillon; SILVA, Nelson do Valle. (1985), “O Charme Discreto do Socialismo Moreno". DADOS - Revista de Ciências Sociais, vol. 28, no 2, pp. 163-192.

SOUZA, Amaury de. (1971), "Raça e Política no Brasil Urbano". Revista de Administração de Empresas, vol. 11, no 4, pp. 61-70.

UNEGRO (União de Negros pela Igualdade). (2011), Balanço Eleitoral do Voto Étnico Negro e Presença dos Negros no Parlamento. Belo Horizonte, União de Negros pela Igualdade.

VALENTE, Ana Lucia. (1986), Política e Relações Raciais: Os Negros nas Eleições Paulistas de 1982. Tese de doutorado, Universidade de São Paulo.

WILLIAMS, Melissa. (2000), Voice, Trust, and Memory: Marginalized Groups and the Failings of Liberal Representation. Princeton, Princeton University Press.

YOUNG, Iris Marion. (2000), Inclusion and Democracy. New York, Oxford University Press. 


\section{Lista de Siglas dos Partidos Políticos}

DEM - Democratas

PCB - Partido Comunista Brasileiro

PCdoB - Partido Comunista do Brasil

PCO - Partido da Causa Operária

PDT - Partido Democrático Trabalhista

PHS - Partido Humanista da Solidariedade

PMDB - Partido do Movimento Democrático Brasileiro

PMN - Partido da Mobilização Nacional

PP - Partido Progressista

PPL - Partido Pátria Livre

PPS - Partido Popular Socialista

PR - Partido da República

PRB - Partido Republicano Brasileiro

PRP - Partido Republicano Progressista

PRTB - Partido Renovador Trabalhista Brasileiro

PSB - Partido Socialista Brasileiro

PSC - Partido Social Cristão

PSD - Partido Social Democrático

PSDB - Partido da Social Democracia Brasileira

PSDC - Partido Social Democrata Cristão

PSL - Partido Social Liberal

PSOL - Partido Socialismo e Liberdade

PSTU - Partido Socialista dos Trabalhadores Unificado

PT - Partido dos Trabalhadores

PTB - Partido Trabalhista Brasileiro

PTC - Partido Trabalhista Cristão

PTdoB - Partido Trabalhista do Brasil

PTN - Partido Trabalhista Nacional

PV - Partido Verde 
RESUMO

Socialismo Moreno, Conservadorismo Pálido? Cor e Recrutamento

Partidário em São Paulo e Rio de Janeiro nas Eleições de 2012

A ausência de determinados grupos - como mulheres, homossexuais, pretos, pardos etc. - da representação política vem se tornando um tema central no debate público e na academia. Contudo, a extensa bibliografia dedicada à subrepresentação política das mulheres no Brasil destoa quando comparada aos poucos trabalhos sobre a marginalidade política dos não brancos. Para ajudar a preencher tal lacuna, este artigo discute os dados de um levantamento sobre a cor dos candidatos a vereador nas eleições ocorridas em 2012 nas cidades de São Paulo e Rio de Janeiro. Diante da carência de registros oficiais sobre a cor autodeclarada dos candidatos, optou-se por submeter suas quase três mil fotos, obtidas no site do Tribunal Superior Eleitoral, à classificação de uma equipe de pesquisadores. Os resultados permitem problematizar a tese que afirma que os partidos de esquerda são mais abertos a não brancos do que legendas de direita. Mais importante ainda, eles indicam que a marginalização dos não brancos da representação não pode ser atribuída exclusivamente a deficiências de recrutamento de candidaturas por parte dos partidos.

Palavras-chave: raça; cor; eleições; recrutamento político; partidos políticos

\section{ABSTRACT \\ Brown Socialism, Pale Conservatism? Color and Party Recruitment in São Paulo and Rio de Janeiro in the 2012 Elections}

The absence of certain groups - such as women, homosexuals, blacks, browns etc. - from political representation has become a central theme in the public debate and academia. However, the extensive bibliography dedicated to the under representation of women in Brazil stands in contrast when compared to the few works on the political marginality of non-whites. In order to fill in this gap, this article discusses the data from a survey on the color of candidates in municipal council elections in 2012 in Rio de Janeiro and São Paulo. Given the lack of official records on the self-declared color of the candidates, almost three thousand photographs, obtained from the Electoral Superior Court, were submitted to classification by a team of researchers. The results allow the authors to question the hypothesis that left-wing parties are more open to non-whites than right-wing denominations. More importantly, they indicated that the marginalization of non-whites from representation cannot be attributed exclusively to shortcomings in recruitment.

Keywords: race; color; elections; political recruitment; political parties 


\section{RÉSUMÉ}

Socialisme Métis, Conservatisme Blanc? Couleur et Recrutement Partisan à São Paulo et Rio de Janeiro dans les Élections de 2012

L'absence de groupes déterminés - femmes, homosexuels, Noirs, métis, etc. de la représentation politique est devenu un thème central du débat public et universitaire. La bibliographie conséquente consacrée à la sous-représentation politique des femmes au Brésil contraste avec la rareté des travaux sur la marginalité politique des non-Blancs. Afin d'aider à combler cette lacune, cet article analyse les données relatives à la couleur des candidats aux élections municipales de 2012 dans les villes de São Paulo et Rio de Janeiro. Face à la pénurie de registres officiels sur la couleur "auto-déclarée" des candidats, nous avons choisi de soumettre environ trois mille photographies de candidats, obtenues sur le site du Tribunal Supérieur Électoral, à la classification d'une équipe de chercheurs. Les résultats ont permis de mettre en perspective l'idée selon laquelle les partis de gauche seraient plus ouverts aux non-Blancs que ceux de droite. Plus important encore, ils indiquent que la marginalisation des non-Blancs de la représentation ne peut être exclusivement attribuée aux déficiences de recrutement des candidats de la part des partis.

Mots-clés: race; couleur; élections; recrutement politique; partis politiques

\section{RESUMEN}

¿Socialismo Moreno, Conservadurismo Pálido? Color y Reclutamiento Partidario en São Paulo y Río de Janeiro en las Elecciones de 2012

La ausencia de determinados grupos - como mujeres, homosexuales, negros, pardos, etc. - de la representación política se ha convertido en un tema central en el debate público y en la academia. Sin embargo, aunque existe ya una extensa bibliografía sobre la sub-representación política de las mujeres en Brasil, lo mismo no puede decirse sobre la marginalidad política de los no blancos. Este artículo busca contribuir a llenar este vacío, discutiendo los datos sobre el color de los candidatos a concejal en las elecciones del año 2012 en las ciudades de São Paulo y Río de Janeiro. Ante la carencia de registros oficiales sobre el color auto-declarado de los candidatos, se optó por presentar sus casi tres mil fotos, obtenidas en la página web del Tribunal Superior Electoral, a la clasificación de un equipo de investigadores. Los resultados permiten cuestionar la tesis que sostiene que los partidos de izquierda son más abiertos a no blancos que las leyendas de derecha. Más importante todavía, éstos sugieren que la marginalización de los no blancos de la representación no puede ser atribuida exclusivamente a las deficiencias del reclutamiento de candidaturas por parte de los partidos.

Palabras clave: raza; color; elecciones; reclutamiento político; partidos políticos 

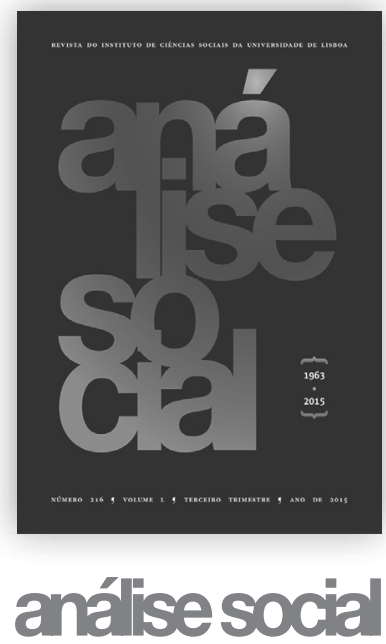

216, L $\left(3 .^{\circ}\right), 2015$

DIRETOR

José Manuel Sobral

EDIÇÃO E PROPRIEDADE

Instituto de Ciências Sociais

da Universidade de Lisboa.

Av. Professor Aníbal

de Bettencourt, 9

1600-189 Lisboa Portugal

Tel. +351 217804700

ASSINATURAS E VENDAS

Clara Cabral

Tel. +351 217804761

analise.social@ics.ulisboa.pt

www.analisesocial.ics.ul.pt
ARTIGOS

$O$ aparelho policial e a construção

do Estado em Portugal, c. 1870-1900

Gonçalo Rocha Gonçalves

Protesto político e atividade policial:

a perceção dos media

Lúcia G. Pais, Sérgio Felgueiras,

André Rodrigues, João Santos e Tiago Varela

A democracia silenciosa: a cooperação

parlamentar portuguesa nos países lusófonos

Bruno Gonçalves Bernardes

Literacia mediática e cidadania:

uma relação garantida?

Paula Cristina Lopes

Circunstâncias globais e tendências recentes no espaço editorial do livro universitário português

Nuno Medeiros

Clusters of religiosity of Portuguese population José Pereira Coutinho

Desenvolvimento e dependência na interpretação sociológica de Fernando Henrique Cardoso Alessandro André Leme

RECENSÕES

O Capital no Século XXI

O Dilema Multicultural

O Partido Republicano Nacionalista (1923-1935):

Uma República para Todos os Portugueses

Geração Europa? Um Estudo sobre

a Jovem Emigração Qualificada para França

O BITUÁRIO

Jack Goody (1919-2015)

por José Manuel Sobral 